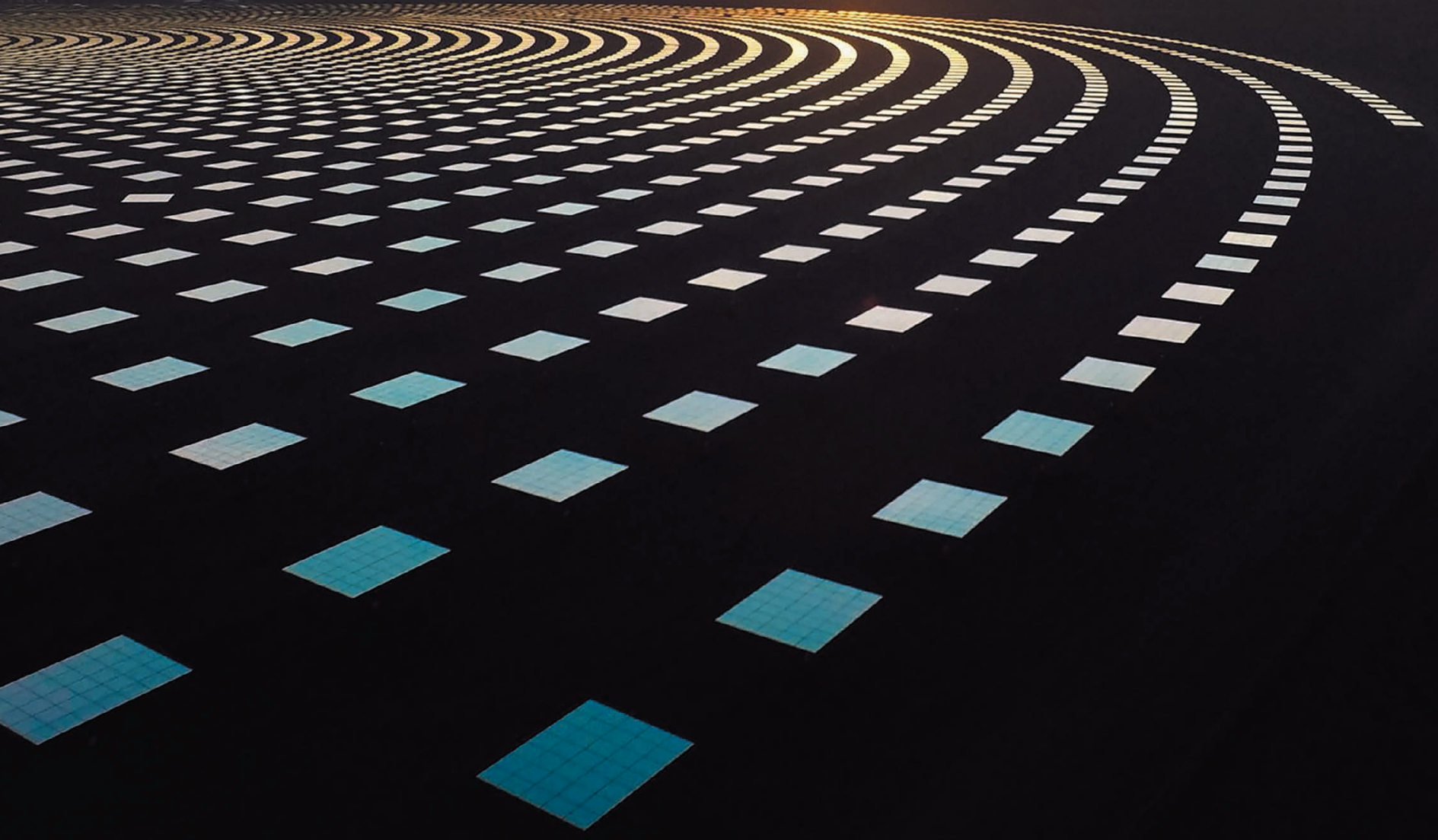

Conventional silicon solar cells account for more than $90 \%$ of global production, yet making them uses energy equivalent to about $10 \%$ of their lifetime output.

\title{
Print flexible solar cells
}

\author{
Pay more attention to developing thin, mass-produced, affordable \\ photovoltaic devices, urge Yi-Bing Cheng and colleagues.
}

$\mathrm{T}$ The future of solar energy depends on a union of new and old technologies. If photovoltaic (PV) devices that turn light into electricity could be mass produced with printing presses, as if they were newspapers or banknotes, they could be affordable and ubiquitous.

Conventional, silicon-based, solar panels are rigid and bulky. Small, thin and flexible PV devices on films are already being made that are lightweight and translucent. These use little material and can generate electricity in low light, even indoors. Integrating them into phones and watches, as well as walls and windows, would transform the world's energy generation, reduce pollution and mitigate climate change.

Yet flexible solar panels face several hurdles. Some are based on harmful substances such as heavy metals, and their manufacture uses hazardous solvents. Others are quick to degrade and inefficient at converting light into electricity. Printers used in the publishing, computing and electronics industries struggle to print $\mathrm{PV}$ materials that need to be built with nanometre precision over many square metres. For all these reasons, printable solar cells are yet to find a foothold in electricity markets.

Most research and development investment goes into conventional silicon solar cells, which account for more than $90 \%$ of global production. Yet manufacturing these uses a lot of energy: equivalent to about $10 \%$ of the cell's lifetime output ${ }^{1}$.

Printed solar cells won't become widespread until they are cheaper and safer to make. Researchers and businesses must work together to improve the efficiency, environmental impact and stability of these cells, scale up their manufacture and plan their market penetration.

\section{PHOTOVOLTAIC PRIMER}

Mass production at low cost is what the solar industry sorely needs. The power that a PV panel generates is proportional to the surface area exposed to sunlight. The world consumes approximately 20,000 terawatthours of electricity each year ${ }^{2}$. Meeting this need would require enough PV devices to cover around 100,000 square kilometres, an area about the size of Iceland.

Such production rates have yet to be achieved. Printed PV devices are typically made from many layers of material on a substrate of conductive glass or plastic. Each layer has a function: semiconductors or sensitizers absorb visible light, and other materials carry electrical charges to electrodes.

Many types of printed PV device are being developed. Some feature organic semiconductors such as polythiophenes. Others use light-absorbing dyes, including ruthenium-based polypyridines. And in quantum-dot solar cells, nanoparticles absorb light. Other examples feature semiconductors with a chalcogen element (sulfur, selenium or tellurium) or contain organic-inorganic light absorbers with a structure similar to that of the mineral 
perovskite. All of these are classed as thinfilm solar cells.

The most efficient are the perovskitebased cells. The latest of these, with just a few years of research behind them (see 'Catching up'), convert $22 \%$ of incident solar power to electrical power ${ }^{3}$. This is more efficient than solar cells made from multicrystalline silicon. But perovskite cells cannot be rolled out commercially yet because they degrade under high humidity and heat.

\section{FINE DETAIL}

Printing layers that are nanometres to micrometres thick - uniformly and without pinholes, and over many square metres - is difficult. The electronics industry commonly uses screen-printing, feeding a paste through a perforated screen ${ }^{4}$. But the layers in printed circuit boards are hundreds of times thicker than those of PV devices. And turning materials into viscous pastes alters their physical and electrical properties.

Other techniques for printing PV devices have been demonstrated in the lab over areas of about 10 square centimetres. These include feeding ink through a slit (slot-die printing), spray-coating the substrate, passing the substrate over a rotating cylinder (gravure printing) and moving a blade over the substrate through an ink supply.

Each technique has a downside. In slotdie printing, for example, the spacing of patterns is hard to control, and gaps reduce the active area of a panel. And in gravure printing, contact between the printer head and the substrate can damage underlying layers. Such drawbacks mean that printed solar cells are less than half as efficient as the best non-printed equivalents ${ }^{5}$.

To print thin, pinhole-free layers over more than one square metre will require intelligent, more-precise equipment and laser processing. An alternative approach would be to develop PV materials that work

\section{CATCHING UP}

Thin-film solar cells that can be processed as solutions and might be printed compete increasingly with silicon photovoltaics.

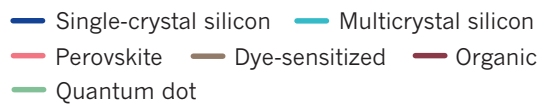
- Quantum dot

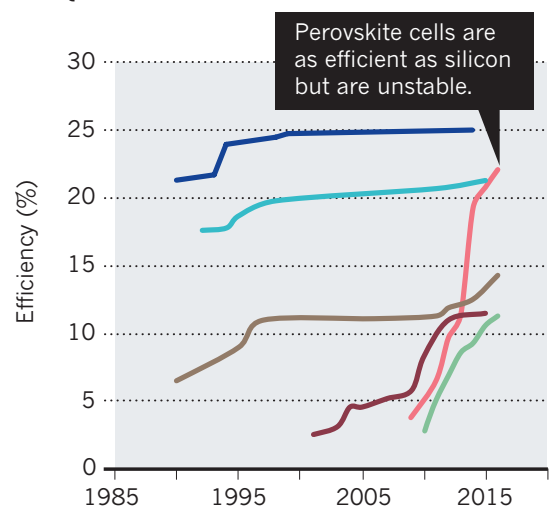

with existing industrial printing methods.

Printing requires that materials can be formed into a liquid, solution or paste. For PV devices, this means using either solutions of chemicals (polymers, dyes or hybrid perovskite, for instance) or dispersions of nanoparticles (such as quantum dots). But many of these can degrade over days to weeks if not properly sealed; and more-stable alternatives, such as silicon, are harder to print.

A balance must also be struck between the efficiency of a device and the environmental impacts of its manufacture. The most efficient thin-film solar cells include toxic or rare materials, such as cadmium, ruthenium and lead, as well as hazardous organic solvents. Indium, another rare element, is a common ingredient in transparent conductive films for PV devices, and its use is expected to rise.

Depleted mineral deposits and low rates of recycling threaten to exhaust indium stocks before the end of the century. Researchers

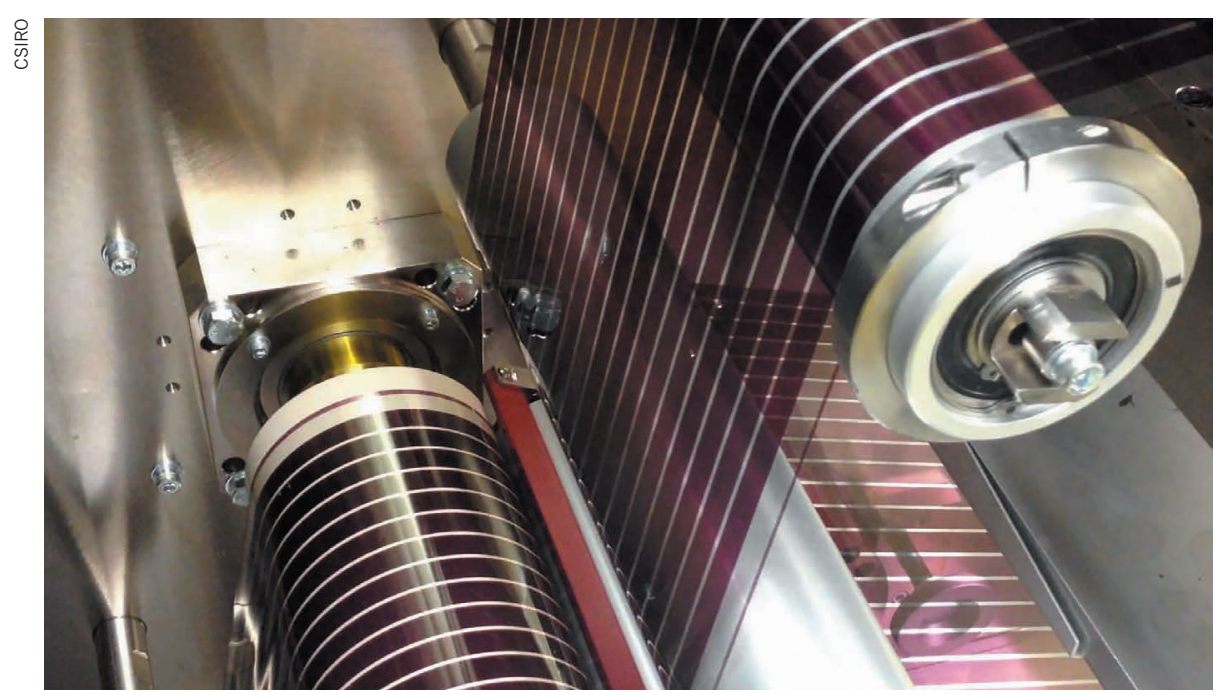

Roll-to-roll printing of organic photovoltaic cells are looking for ways to use abundant materials that can be processed in solution to make efficient devices with little toxic waste. For example, carbon-based electrodes and layers use less precious metal ${ }^{6}$. At present, such designs are often less efficient than others.

\section{WHAT NEXT?}

The huge success of silicon panels has become a hurdle for emerging technologies. The manufacturers of silicon-based PV devices share materials, equipment and practices with sibling industries, such as computing. Developers of printable devices are isolated. And the maturity of the silicon industry means there is little urgency to develop alternatives. Capital investment and product commercialization are perceived as risky, given that printable PV devices are still in development.

Government funding is needed to catapult such devices from a nascent to a competitive state, as happened in China with the silicon PV industry. Market penetration should be developed in stages. Early printable PV devices should target weaknesses in silicon-based technologies, such as their poor performance in low light and their lack of portability. The next wave should complement silicon solar cells and, ideally, be integrated with them. For example, silicon-perovskite devices would harvest a greater fraction of incoming sunlight than silicon devices alone could do.

If printed technologies can capture 5\% of the PV market, their advantages should ensure that they play an ever-increasing part in meeting growing demands for renewable energy.

Yi-Bing Cheng is professor of materials science and engineering at the State Key Lab of Advanced Technology for Materials Synthesis and Processing, Wuhan University of Technology, China, and at Monash University, Clayton, Victoria, Australia. Alex Pascoe is a research fellow at Monash University, Clayton, Victoria, Australia. Fuzhi Huang and Yong Peng are professors at the State Key Lab of Advanced Technology for Materials Synthesis and Processing, Wuhan University of Technology, China.

1. Photovoltaics Report (Fraunhofer Institute for Solar Energy Systems, 2016); available at go.nature.com/2eusg7r

2. Key World Energy Statistics (IEA, 2016); available at go.nature.com/2ewux $1 \mathrm{w}$

3. Best Research-Cell Efficiencies (US National Renewable Energy Laboratory); available at go.nature.com/2exvaq0

4. Das, R. Printing Equipment for Printed Electronics 2015-2025: Market Opportunities for Printing, Curing and Integration Equipment (IDTechEx, 2015).

5. Ye, M., Hong, X., Zhang, F. \& Liu, X. J. Mater. Chem. A 4, 6755-6771 (2016).

6. Mei, A. et al. Science 345, 295-298 (2014). 